\title{
Successful Withdrawal of Thyroid Hormone Therapy in Nursing Home Patients
}

\author{
Patrick P. Coll, MB, BCh, and Nicolas N. Abourizk, $M D$
}

Background: Studies of community-dwelling patients have indicated that substantial numbers of patients might have had thyroid hormone therapy prescribed inappropriately and that thyroid hormone therapy in some can be discontinued without adverse effects or evidence of clinical hypothyroidism. We wanted to find out whether thyroid hormone therapy in selected nursing home patients could be withdrawn without adverse effect.

Metbods: Participants for the study were drawn from four skilled nursing facilities in Connecticut. All patients on thyroid hormone therapy who resided in one of the four facilities at the time the study began were eligible if they met the inclusion criteria and gave consent to participate in the study. We measured baseline thyrotropin (TSH) levels and reduced thyroid hormone therapy by approximately onehalf if baseline TSH levels were $7 \mathrm{mU} / \mathrm{L}$ or less. If at a 1-month follow-up measurement a patient's TSH level was $7 \mathrm{mU} / \mathrm{L}$ or less, we discontinued thyroid hormone therapy. If $1 S H$ levels remained $7 \mathrm{mU} / \mathrm{L}$ or less at the next follow-up measurement 1 month later, we measured the free thyroxine $\left(T_{4}\right)$ level. If the free $T_{4}$ level was normal, the patient remained off thyroid hormone therapy, and a final TSH value was measured after a further 2 months.

Results: There were 915 patients residing at the four homes at the time the study began. One hundred fifteen were on thyroid hormone therapy; 40 had elevated TSH levels in their nursing home records; and 31 refused to participate in the study. Twenty-two patients were excluded because they died or were discharged before completion of the study, had an elevated baseline TSH reading, or were taking medications that could complicate the accurate measurement of TSH. Twenty-two patients began hormone withdrawal. One patient had an increase in psychiatric symptoms during the withdrawal phase. No other adverse effects were noted. Eleven patients $(50 \%)$ had the thyroid hormone therapy withdrawn successfully.

Conclusion: Thyroid hormone therapy was successfully withdrawn from one half of the nursing home residents studied. Previous studies conducted in community-dwelling patients have shown similar findings. Many older patients began taking thyroid hormone therapy when younger either for inappropriate reasons or for what turned out to be transient hypothyroidism. If the findings of this study are generalizable for other nursing home residents, there are important implications for health and health care costs. (J Am Board Fam Pract 2000;13:403-7.)

The prevalence of hypothyroidism increases with age and is more common in older women than older men. Framingham data on community-dwelling patients showed a prevalence of $5.9 \%$ for women and $2.3 \%$ for men older than 60 years of age. ${ }^{1}$ Data from a community-dwelling population

Submitted, revised, 11 April 2000.

From the Departments of Family Medicine and Medicine (Geriatrics) (PPC), University of Connecticut Center on Aging, Farmington; and the Section of Endocrinology and Diabetes (NNA), St. Francis Hospital and Medical Center, Hartford, Conn. Address reprint requests to Patrick P. Coll, MB, BCh, Center on Aging, MC-5215, University of Connecticut Health Center, Farmington, CT 06030-5215.

This work was supported by the American Academy of Family Physicians Foundation (grant \#G9519). Data were presented at the Gerontological Society of America Annual Meeting, Philadelphia, November 1998. aged more than 60 years in Massachusetts showed a prevalence of $5.9 \% .^{2}$ Both studies used a thyrotropin (TSH) level of more than $10 \mathrm{mU} / \mathrm{L}$ to make the diagnosis. Data from Norway showed previously diagnosed hypothyroidism in $3.5 \%$ of women older than 70 years and in no men older than 70 years. ${ }^{3}$ Eleven percent of patients in a large state veterans' home had evidence of hypothyroidism. ${ }^{4}$ This finding might underestimate the prevalence of hypothyroidism in nursing homes because most residents at this home were men. Chronic autoimmune thyroiditis and previous treatment for hyperthyroidism are the most common causes of clinical hypothyroidism. ${ }^{5,6}$

Previous studies of community-dwelling patients have indicated that many patients might have 
started thyroid hormone therapy inappropriately. Older patients might have begun therapy years ago when the laboratory evaluation of thyroid disorders was less accurate and when some physicians treated fatigue, weight gain, hair loss, and hypercholesterolemia with thyroid hormone therapy without laboratory evidence of hypothyroidism. Spontaneous resolution of transient hypothyroidism can occur. In several studies community-dwelling patients have had thyroid hormone therapy discontinued without adverse effect and without evidence of subsequent clinical hypothyroidism. ${ }^{8-10}$ Successful withdrawal of thyroid hormone therapy from nursing home patients has not previously been reported.

\section{Methods}

Four skilled nursing facilities were selected for inclusion in the study. Approval for the study was obtained from the Saint Francis Hospital and Medical Center Institutional Review Board. A list was generated for each home of all resident patients who were on thyroid hormone therapy at the time the study started. The nursing home records of these patients were reviewed by a nurse. Patients were excluded from the study if a TSH level of more than $10 \mathrm{mU} / \mathrm{L}$ was noted anywhere in their records, if they were taking lithium or amiodarone at the time the study started, or if they had a history of thyroid hormone therapy because of a thyroid nodule or goiter. All remaining patients or their legal guardians were asked to sign a consent form to participate in the blood measurement and thyroid hormone therapy withdrawal components of the study. Each patient's attending physician was also asked to agree to have the patient participate in the withdrawal phase of the study.

All eligible patients then had a neck examination performed by one of the two authors and were excluded from the study if they had a palpable thyroid nodule. All remaining patients had blood drawn and sent to the laboratory of a community hospital for a TSH measurement. The assay used was an ultrasensitive human thyroid-stimulating hormone microparticle enzyme immunoassay ( $\mathrm{Ab}$ bott) with a sensitivity of $0.05 \mathrm{mU} / \mathrm{L}$. Patients with a TSH of more than $7 \mathrm{mU} / \mathrm{L}$ were excluded from the study, and their primary care physicians were informed that they had an elevated TSH level.

All patients with a TSH level of $7 \mathrm{mU} / \mathrm{L}$ or less had their thyroid hormone therapy dose reduced by as close to one half as was practically possible. If they were taking $125 \mu \mathrm{g} / \mathrm{d}$, their dose was reduced to $75 \mu \mathrm{g} / \mathrm{d}$, and if they were taking $75 \mu \mathrm{g} / \mathrm{d}$, their dose was reduced to $50 \mu \mathrm{g} / \mathrm{d}$. A follow-up TSH level was measured approximately 1 month later. If a patient's level was more than $7 \mathrm{mU} / \mathrm{L}$, that patient was excluded from the study and resumed his or her original dose of thyroid hormone therapy. The rest of the patients had their thyroid hormone therapy discontinued. These patients had a further TSH level measured approximately 1 month later. Patients with values more than $7 \mathrm{mU} / \mathrm{L}$ were excluded from the study and resumed their original dose of thyroid hormone therapy. Their attending physicians were notified that thyroid hormone therapy doses might be too high. If the TSH level from this blood draw was $7 \mathrm{mU} / \mathrm{L}$ or less, the same aliquot of blood was used to measure a free thyrotropin $\left(\mathrm{T}_{4}\right)$ level using the equilibrium dialysis method. If the free $T_{4}$ level was more than 0.8 $\mathrm{ng} / \mathrm{dL}$, the patient stayed off thyroid hormone therapy, and had a final TSH level measured 2 months later, ie, 3 months after discontinuing thyroid hormone therapy. If the level was less than 7 $\mathrm{mU} / \mathrm{L}$, the patient remained off thyroid hormone therapy.

TSH is an accurate measure of thyroid status unless the patient has had recent thyrotoxicosis; is receiving dopamine, octreotide, or steroids; or is very sick or recovering from a recent severe illness. ${ }^{5}$ All the attending physicians whose patients had a complete withdrawal from thyroid hormone therapy were informed of the patient's new status, as were the medical directors of the facilities where each of the patients resided.

Patients were not monitored for a change in condition associated with the reduction or withdrawal of thyroid hormone therapy. Nursing staff and patients' attending physicians were notified that dose reductions were taking place for their patient, and they were asked to notify the investigators if a change in condition was noted.

\section{Results}

At the time the study was initiated, 915 residents lived in the four study homes. Of these patients, $115(12.6 \%)$ were on thyroid hormone therapy. Forty patients had evidence of an elevated TSH level in their nursing home medical record and were eliminated from the study. Thirty-one pa- 
Table 1. Distribution of Patients, Exclusion Criteria, and Results at the Four Study Homes.

\begin{tabular}{|c|c|c|c|c|c|}
\hline Patients & $\begin{array}{c}\text { Home } 1 \\
\text { No. }\end{array}$ & $\begin{array}{c}\text { Home } 2 \\
\text { No. }\end{array}$ & $\begin{array}{c}\text { Home } 3 \\
\text { No. }\end{array}$ & $\begin{array}{c}\text { Home } 4 \\
\text { No. }\end{array}$ & $\begin{array}{l}\text { Total } \\
\text { No. }\end{array}$ \\
\hline Reside in home & 334 & 175 & 262 & 144 & 915 \\
\hline On hormone replacement therapy & 56 & 29 & 20 & 10 & 115 \\
\hline Elevated TSH level in record & 28 & 3 & 9 & 0 & 40 \\
\hline Refused consent & 6 & 14 & 3 & 8 & 31 \\
\hline Met additional exclusion criteria & 11 & 6 & 4 & 1 & 22 \\
\hline Withdrawal initiated & 11 & 6 & 4 & 1 & 22 \\
\hline Hormone withdrawal successful & 8 & 2 & 0 & 1 & 11 \\
\hline
\end{tabular}

TSH-thyroid-stimulating hormone.

tients were eliminated from the study because either they, their legal guardians, or their physicians refused to give consent for participation in the withdrawal phase. A further 22 patients were excluded from the study because (1) they were discharged from the facility or died before the completion of the study, (2) they had an elevated baseline TSH reading, or (3) they were taking a medication that would influence the clinical interpretation of thyroid function tests. Twenty-two patients entered the withdrawal phase of the study (Table 1).

The mean age of patients entering the withdrawal stage of the study was 78 years (range 50 to 90 years). Twenty of the 22 patients entering the withdrawal phase were women.

Eleven patients had a TSH reading of less than $7 \mathrm{mU} / \mathrm{L}$ after at least 3 months off thyroid hormone therapy and were considered to have had the hormone successfully withdrawn (Table 2). One patient developed marked increase in agitation and restlessness following an initial dose reduction. This patient had a history of psychiatric illness. Although at the time the patient's symptoms were not thought to be related to reducing thyroid hormone therapy, the initial dose of thyroid hormone therapy was reintroduced at the request of the patient's physician. TSH levels increased to more than $7 \mathrm{mU} / \mathrm{L}$ in 7 patients after the initial dose reduction (Table 3) and in 3 more patients after discontinuation of thyroid hormone therapy. No patient had an abnormal free $T_{4}$ reading. Patients were more likely to have a clinically important increase in TSH levels after dose reduction if initially they were taking more than $50 \mu \mathrm{g} / \mathrm{d}$ of thyroid hormone therapy. Even so, 3 of 10 patients taking $50 \mu \mathrm{g} / \mathrm{d}$ or less had their TSH levels increase to more than $7 \mathrm{mU} / \mathrm{L}$ after dose reduction.

Table 2. Patients Who Had Thyroid Hormone Therapy Successfully Withdrawn.

\begin{tabular}{|c|c|c|c|c|c|c|c|c|}
\hline \multirow[b]{2}{*}{ Patient } & \multicolumn{2}{|c|}{ Baseline Value } & \multicolumn{6}{|c|}{ Withdrawal Value } \\
\hline & $\begin{array}{l}\text { THT } \\
\mu \mathrm{g} / \mathrm{d}\end{array}$ & $\begin{array}{c}\text { TSH } \\
\mathrm{mU} / \mathrm{L}\end{array}$ & $\begin{array}{l}\text { THT } \\
\mu \mathrm{g} / \mathrm{d}\end{array}$ & $\begin{array}{c}\text { TSH } \\
\mathrm{mU} / \mathrm{L}\end{array}$ & $\begin{array}{l}\text { THT } \\
\mu \mathrm{g} / \mathrm{d}\end{array}$ & $\begin{array}{c}\mathrm{TSH} \\
\mathrm{mU} / \mathrm{L}\end{array}$ & $\begin{array}{c}\text { Free } T_{4} \\
n g / d L\end{array}$ & $\begin{array}{c}\text { Final TSH } \\
m U / L\end{array}$ \\
\hline 1 & 100 & 0.545 & 50 & 1.69 & 0 & 3.74 & 2.7 & 3.14 \\
\hline 2 & 25 & 4.56 & 0 & 4.92 & 0 & 6.36 & 4.9 & 4.91 \\
\hline 3 & 100 & 0.05 & 50 & 2.70 & 0 & 4.56 & 1.2 & 3.09 \\
\hline 4 & 50 & 3.51 & 25 & 5.42 & 0 & 5.61 & 9.8 & 4.93 \\
\hline 5 & 50 & 2.60 & 25 & 3.27 & 0 & 3.78 & 1.3 & 3.35 \\
\hline 6 & 100 & 0.04 & 50 & 0.39 & 0 & 2.27 & 0.5 & 2.72 \\
\hline 7 & 50 & 2.87 & 25 & 5.03 & 0 & 4.44 & 0.6 & 3.31 \\
\hline 8 & 75 & 0.87 & 50 & 1.73 & 0 & 2.68 & 8.0 & 3.90 \\
\hline 9 & 25 & 4.51 & & & 0 & 5.46 & 1.6 & 5.78 \\
\hline 10 & 25 & 0.69 & & & 0 & 0.56 & 0.9 & 0.05 \\
\hline 11 & 25 & 4.79 & & & 0 & 5.19 & 1.8 & 4.11 \\
\hline
\end{tabular}

THT -thyroid hormone therapy, TSH-thyroid-stimulating hormone, $\mathrm{T}_{4}$-thyroxine. 
Table 3. Patients Requiring the Reintroduction of Baseline Thyroid Hormone Therapy.

\begin{tabular}{|c|c|c|c|c|c|c|}
\hline \multirow[b]{2}{*}{ Patient } & \multicolumn{2}{|c|}{ Baseline Value } & \multicolumn{4}{|c|}{ Withdrawal Value } \\
\hline & $\begin{array}{l}\text { THT } \\
\mu \mathrm{g} / \mathrm{d}\end{array}$ & $\begin{array}{c}\text { TSH } \\
\mathrm{mU} / \mathrm{L}\end{array}$ & $\begin{array}{l}\text { THT } \\
\mu \mathrm{g} / \mathrm{d}\end{array}$ & $\begin{array}{c}\text { TSH } \\
\mathrm{mU} / \mathrm{L}\end{array}$ & $\begin{array}{l}\text { THT } \\
\mu \mathrm{g} / \mathrm{d}\end{array}$ & $\begin{array}{c}\text { TSH } \\
\mathrm{mU} / \mathrm{L}\end{array}$ \\
\hline 1 & 50 & 3.40 & 25 & 4.75 & 0 & 10.13 \\
\hline 2 & 125 & 2.43 & 75 & 5.35 & 0 & 12.48 \\
\hline 3 & 50 & 3.30 & 25 & 5.63 & 0 & 10.59 \\
\hline 4 & 175 & 4.15 & 100 & 13.43 & & \\
\hline 5 & 150 & 3.91 & 75 & 24.44 & & \\
\hline 6 & 50 & 4.78 & 25 & 13.99 & & \\
\hline 7 & 125 & 0.24 & 75 & 7.12 & & \\
\hline 8 & 100 & 0.67 & 50 & 7.87 & & \\
\hline 9 & 75 & 4.71 & 50 & 7.75 & & \\
\hline 10 & 75 & 0.69 & 50 & 8.61 & & \\
\hline 11 & 125 & 4.74 & 75 & 1.40 & - & $\begin{array}{l}\text { Developed } \\
\text { psychiatric } \\
\text { symptoms }\end{array}$ \\
\hline
\end{tabular}

THT-thyroid hormone therapy, TSH-thyroid-stimulating hormone.

\section{Discussion}

This study shows for the first time that substantial numbers of nursing home residents are inappropriately receiving thyroid hormone therapy and can successfully and safely have their thyroid hormone therapy discontinued. Although $50 \%$ of those who had their thyroid hormone therapy reduced also had the hormone successfully withdrawn, only $10 \%$ of all patients had thyroid hormone therapy successfully withdrawn. One third of the patients excluded from the study, however, were excluded because they, a family member, or their physician, refused consent to participate. Other than the psychiatric symptoms noted in 1 patient, there were no reports during the study of any negative impact on the clinical status of the patients withdrawn. Reduction and discontinuation of thyroid hormone therapy are safe even for patients subsequently confirmed to be hypothyroid, as long as close attention is paid to follow-up measures of thyroid function. The study protocol might have been overly cautious; it would have been reasonable to discontinue thyroid hormone therapy in all patients with a normal baseline TSH level instead of the stepped reduction used here.

When caring for an older patient, especially those in nursing homes, it can be difficult for the clinician to obtain from the patient, family, or medical record why thyroid hormone therapy was begun and whether the diagnosis was arrived at cor- rectly using conclusive measures of thyroid function. It is frequently a daunting task to obtain all of the patient's medical records. Efforts should be made to obtain that part of the record pertaining to the diagnosis of hypothyroidism. If those records are unavailable, it is reasonable to initiate withdrawal based on information available in the patient's nursing home record alone.

This study was conducted in four nursing homes in one geographic area. Most study subjects who had thyroid hormone therapy successfully withdrawn resided in home 1 . Although it is possible that the results obtained are due to the practice habits of one or a few physicians, all the patients studied were on thyroid hormone therapy when they were first admitted to their respective nursing homes, and they came from disparate geographic locations. We cannot be sure that the patients did not suffer from some subtle form of adverse clinical effect after the withdrawal of thyroid hormone therapy, but there is no existing body of clinical evidence to suggest that they would.

Although none of the patients was thought to be taking too much thyroid medication at the beginning of the study, there is the possibility of subclinical adverse effects from the unnecessary use of thyroid hormone therapy in elderly patients. Banovac et al ${ }^{11}$ found that patients on long-term thyroid hormone therapy with elevated $T_{4}$ levels had a high incidence of abnormalities in myocardial contractility. Increased risk of breast cancer has been described in patients on long-term thyroid hormone therapy, but the finding has not been substantiated in subsequent studies. ${ }^{12-14}$ The greatest potential risk of a subclinical adverse effect because of the inappropriate use of thyroid hormone therapy in older nursing home residents is osteoporosis. It is clear from several studies that excessive or suppressive doses of thyroid hormone result in a decrease in bone density. ${ }^{15-19}$ It is less certain, but an increasing body of evidence suggests that even therapeutic doses of thyroid hormone contribute to decreased bone density. ${ }^{20-22} \mathrm{Kung}$ and Pun, ${ }^{22}$ in their study of 26 premenopausal women receiving physiologic doses of levothyroxine compared with age-matched control women, found that femoral bone density was between $5 \%$ and $15 \%$ less in the women on thyroid hormone therapy. The mean duration of hormone therapy in these patients was 7.5 years, and the mean dose of thyroid hormone was $106 \mu \mathrm{g}$. It does appear, however, that close 
control and monitoring of thyroid hormone therapy can avoid reductions in bone density. ${ }^{23-24}$ No studies have been published to date on the effect of inappropriate thyroid hormone therapy on bone mineral density.

Physicians with nursing home patients on thyroid hormone therapy should evaluate whether the patient is taking the medication for an appropriate indication. If the patient's history, examination, or available medical records do not indicate an appropriate indication, the dose should be reduced or therapy should be discontinued, and thyroid function tests should be followed in a fashion similar to that used in this study.

\section{References}

1. Sawin CT, Castelli WP, Hershman JM, McNamara $P$, Bacharach $P$. The aging thyroid. Thyroid deficiency in the Framingham Study. Arch Intern Med 1985;145:1386-8.

2. Sawin CT, Chopra D, Azizi F, Mannix JE, Bacharach $\mathrm{P}$. The aging thyroid. Increased prevalence of elevated serum thyrotropin levels in the elderly. JAMA 1979;242:247-50.

3. Brochmann H, Bjoro T, Gaarder PI, Hanson F, Frey HM. Prevalence of thyroid dysfunction in elderly subjects. A randomized study in a Norwegian rural community (Naeroy). Acta Endocrinol (Copenh) 1988;117:7-12.

4. Drinka PJ, Nolten WE, Voeks S, Langer E. Thyroid stimulating hormone elevation without antithyroid antibody elevation in nursing home patients. J Am Geriatr Soc 1991;39:1000-1.

5. Mandel SJ, Brent GA, Larsen PR. Levothyroxine therapy in patients with thyroid disease. Ann Intern Med 1993;119:492-502.

6. Dayan CM, Daniels GH. Chronic autoimmune thyroiditis. N Engl J Med 1996;335:99-107.

7. Takasu N, Yamada T, Takasu M, et al. Disappearance of thyrotropin-blocking antibodies and spontaneous recovery from hypothyroidism in autoimmune thyroiditis. N Engl J Med 1992;326:513-8.

8. Rizzolo PJ, Fischer PM. Re-evaluation of thyroid hormone status after long-term hormone therapy. $J$ Fam Pract 1982;14:1017-21.

9. Jones A, Corbett DG, Davies JB, et al. Evaluation of long term thyroid replacement treatment. Swansea Vocational Training Scheme. Br Med J (Clin Res Ed) 1985;291:1476-8.

10. Sawin CT, Geller A, Hershman JM, Castelli W, Bacharach $P$. The aging thyroid. The use of thyroid hormone therapy in older persons. JAMA 1989;261: 2653-5.

11. Banovac K, Papic M, Bilsker MS, Zakarija M, McKenzie JM. Evidence of hyperthyroidism in appar- ently euthyroid patients treated with levothyroxine. Arch Intern Med 1989;149:809-12.

12. Kapdi CC, Wolfe JN. Breast cancer. Relationship to thyroid supplements for hypothyroidism. JAMA 1976;236:1124-7.

13. Shapiro S, Slone D, Kaufman DW, et al. Use of thyroid supplements in relation to the risk of breast cancer. JAMA 1980;244:1685-7.

14. Leese GP, Jung RT, Guthrie C, Waugh N, Browning MC. Morbidity in patients on L-thyroxine: a comparison of those with a normal TSH to those with a suppressed TSH. Clin Endocrinol (Oxf) 1992; 37:500-3.

15. Ross DS, Neer RM, Ridgway EC, Daniels GH. Subclinical hyperthyroidism and reduced bone density as a possible result of prolonged suppression of the pituitary-thyroid axis with $\mathrm{L}$-thyroxine. Am J Med 1987;82:1167-70.

16. Paul TL, Kerrigan J, Kelly AM, Braverman LE, Baran DT. Long-term $\mathrm{L}$-thyroxine therapy is associated with decreased hip bone density in premenopausal women. JAMA 1988;259:3137-41.

17. Stall GM, Harris S, Sokoll LJ, Dawson-Hughes B. Accelerated bone loss in hypothyroid patients overtreated with L-thyroxine. Ann Intern Med 1990;113: 265-9.

18. Taelman P, Kaufman JM, Janssens $X$, Vandecauter $\mathrm{H}$, Vermeulen $\mathrm{A}$. Reduced forearm bone mineral content and biochemical evidence of increased bone turnover in women with euthyroid goitre treated with thyroid hormone. Clin Endocrinol (Oxf) 1990; 33:107-17.

19. Diamond T, Nery L, Hales I. A therapeutic dilemma: suppressive doses of thyroxine significantly reduce bone mineral measurements in both premenopausal and postmenopausal women with thyroid carcinoma. J Clin Endocrinol Metab 1991;72: 1184-8.

20. Greenspan SL, Greenspan FS, Resnick NM, Block JE, Friedlander AL, Genant HK. Skeletal integrity in premenopausal and postmenopausal women receiving long-term L-thyroxine therapy. Am J Med 1991;91:5-14.

21. Adlin EV, Maurer AH, Marks AD, Channick BJ. Bone mineral density in postmenopausal women treated with $\mathrm{L}$-thyroxine. Am J Med 1991;90:360-6.

22. Kung AW, Pun KK. Bone mineral density in premenopausal women receiving long-term physiological doses of levothyroxine. JAMA 1991;265:268891.

23. Wartofsky L. Use of sensitive TSH assay to determine optimal thyroid hormone therapy and avoid osteoporosis. Annu Rev Med 1991;42:341-5.

24. Marcocci C, Golia F, Bruno-Bossio G, Vignali E, Pinchera A. Carefully monitored levothyroxine suppressive therapy is not associated with bone loss in premenopausal women. J Clin Endocrinol Metab 1994;78:818-23. 